DE DE GRUYTER OPEN
Journal of Intercultural Management

Vol. 6, No. 4, part II, December 2014, pp. 25-34

DOI 10.2478/joim-2014-0054

Ryszard Królik ${ }^{1}$

Politechnika Częstochowska

\title{
The Impact of Conflict Management on Organizational Culture in Family Business
}

\begin{abstract}
In the article there is presented the connection between the strategy of conflict management and the level of organizational culture in the family business. There was put forward the argument to formalize the family and business relationships by implementing the internal constitution, which helps to manage conflict management effectively. Particularly, it allows to reduce the movement of conflicts between the enterprise and the family by means of the improvement in, among others, the internal communication.
\end{abstract}

Key words: family business, organizational culture, conflict management.

\section{Introduction}

All members of an organization come from the society, which determines their behavior and influences their organizational behavior both directly and indirectly. The culture of the society is the whole of spiritual and material achievements of the society, passed from generation to generation, beliefs and practices of its members, the adopted patterns of behavior. One of the features of the culture is the ability to spread, not only over the next generations, but also by means of contacts, verbal and non-verbal, between individuals and groups ethnically different. The most frequently, the interpenetration of cultures enriched the societies with some new elements and the modes of conduct, bringing about the civilization development. It also raised the awareness of own autonomy. Too big cultural differences often led to conflicts inside the organization.

The aim of this paper is to describe the impact that conflict has on the organizational culture in family business, and the possibility of him directing.

1 ryszkrolik@op.pl 
Followed by the study is the phenomenological analysis of content available in the literature and research.

\section{The significance of organizational culture in the family business}

When defining the enterprise culture, it is important to put emphasis on learning history and the geopolitical environment of the societies whose members work in the enterprise. On the basis of the above statements, it is possible to formulate the definition of organizational culture as a set of norms and intellectual values which characterize a given organization, developing for a long time, whose result is the formation of some patterns of conduct for a given social group and a certain hierarchy of values [Trutkowski 2006, p. 153].

The forms of organizational culture and patterns of behavior, distinguishing them from others, are mostly regulated by the organizational system of the enterprise and the kind of its business activity, the systems of the organization of production, the circulation of documents, patterns of behavior and norms predominating in a given group.

While making an attempt to define the family business one aims at specifying social, economic and legal factors describing this phenomenon. Enterprises defined as family businesses, for many years, evolved in different directions, depending on the economic, social and legal conditions of the specific economies. Nowadays, the family business must be treated in a multidimensional way. It is difficult to indicate appropriate criteria specifying the family business due to the form of ownership, management model or the scope of activity. Moreover, this term consists of the two terms coming from different sciences with a different record of origins, and theoretically, having two aims of existence. While establishing the definition of the family business, it is necessary to include some economic, psychological, sociological, historic and legal factors as well as the ones connected with management [Safin 2007, p. 17].

The definition which best integrates the family with the business activity was given by B.C.J. Lievegoed [Safin 2007, p. 22], in which the enterprise may be defined as the family business when:

- spouses and the next generation take an active part in managing the enterprise,

- the family culture was transferred to the enterprise organizational culture,

- the social behavior of all family members is transferred to the ground of the enterprise,

- the status of the enterprise determines the status and position of the family, which participates both in the generated profit and the funding of the enterprise activity and the suffered losses.

This definition, including both the economic and social aspect of the family business, is, however, only the characteristics of the model enterprise which, e.g. 
in a social aspect2, is not an ideal solution. On the other hand, as far as financial issues are concerned, the company has a large margin of financial protection by the readiness of family members to give up their own income for the benefit of the enterprise, while protecting its reputation and the possessions of the entire family.

The full definition is given by the following authors: Jeżak, Winnicka-Popczyk, Popczyk [2004, p.19], defining the family business as an enterprise of unlimited legal form whose capital, either in total or in vast majority, is possessed by the family, where at least one family member exerts a significant influence on the management or occupies the managerial position themselves with the intention of long-term maintenance of the business in the hands of the family.

The family resources of the family enterprise are unique and of a great significance for its competitive advantage [Tomski 2013, p. 124]. For the family business, the family is a hidden, additional potential, most of all, as the intellectual support, 'the store of ideas', as the catalyst relieving tension inside the organization and the cultural pattern of behavior, obviously if there are no pathologies in the family.

Organizational culture in the family business refers to the common views and the way of thinking of the whole family, involved (at least spiritually) in the family enterprise. This culture reflects the cultural norms and values transferred from generation to generation and acknowledged as the model. There count, above all, individual features of the character of the main founder and owner. However, there are also important: the influence of the most inner circle of the founder on their attitude, the tradition, and the characteristics of the society the family members come from. The system of values and moral and ethical attitudes, which may include hard work, long-term involvement, sacrifice for some matters of the family business, is a rather conservative attitude. Such attitude stabilizes and directs the enterprise activities, which, from the point of view of the family, is a positive phenomenon, whereas from the perspective of the enterprise, with the dynamically changing economic environment, may impede the reactions of the enterprise to some external factors. Therefore, the conservatism in this case is a kind of 'inertia mass', loading ballast for the enterprise.

\section{Conflicts in the organization}

Each company, while looking for its market niche, subconsciously aims at the achievement of stabilization. Such a way of regarding the organization inevitably leads to discrepancies and to the rise of conflicts. Paradoxically, in accordance with the contemporary theories of management, there is not potentially better way

2 The author has in mind the transfer of the family behavior to the ground of the enterprise, the one which has a negative impact in the area of management and consequently, the financial performance of the enterprise and the transfer of problems from the enterprise to the family ground. 
towards the organizational development than coming through subsequent stages of experiencing and solving conflicts. In the current instability in the economy and with the low efficiency of the forecasting of economic events, there arise a lot of conflicts. They result from the tension occurring as a result of the autonomous thinking of individual members of an organization, and connected with different points of views on solving problems.

Conflict is an element permanently connected with the life of the man. It may be a driving force of their development or a barrier to their activities.

The most frequent causes of conflicts are:

- the differences in views, personalities as well as the differences in understanding and recognizing the norms of behavior (frequently resulting from the differences in gender and age)

- faulty coordination of the project teams performing e.g. different goals

- unclear responsibility

- 'unfair' rewarding and sharing the resources

- distortion and hype in communication

- improper style of the enterprise management.

In the framework of the conflicts mentioned above, it is possible to make a distinction on account of the relationships:

- internal conflict of a given person,

- conflict between groups,

- conflict between an individual and a group,

- conflict between individuals,

- conflict between organizations,

- misunderstood competition (fight, disturbing the other party in the achievement of the goal).

All kinds of conflicts may be divided into [Kowalczuk, Sieczyński 1987, p. 222]:

- overt and covert,

- rational and irrational,

- creative and destructive.

Overt conflicts may take a form of criticism or complaints and verbal skirmishes between individuals or group representatives.

Covert conflicts are more difficult to diagnose, and therefore, more dangerous for the organization. In these conflicts there is no direct confrontation.

The reason of rational conflict is the objective assessment of the situation. A fast solution of such a conflict usually improves the overall situation in comparison with the previous condition, assuming that it is an overt conflict.

In case of irrational conflict, diagnosing its reasons is difficult since they have subjective grounds, resulting from e.g. general well-being, prejudice towards another person or errors in receiving verbal and non-verbal signals. 
Creative and destructive conflicts influence the social structure of the organization and the processes connected with the development of strategic goals [Kowalczuk, Sieczyński 1987, pp. 222-223]. The conflict itself, during its course, always disorganizes the processes in the enterprise, and only the end result classifies it to one of the two mentioned above.

The basic sources of conflicts in the family business, apart from the traditional ones, are different views of family members both the ones employed and not employed in the company on the basic goals realized by the enterprise. The periods bringing about most conflicts are transitional moments such as changes in legislation, economic conditions (external factors) and succession, employing younger generation, change of ownership and passing leadership to the hands of others. Then, in the border areas (family, company, ownership) [Safin 2007, p. 30] there occur points of confrontation, creating barriers to the flow of routine and decision-making information. In these places there are interferences and the feedback of intellectual system caused by the processes of the emotional system.

\section{Conflict management in the family business}

The conflict is a constant element in the man's life. All discrepancies the man comes across, result from the decisions taken and the differences between the vision of the future and the reality. In the economy, the conflict may be regarded as an attribute of the enterprise activity. Solving conflicts is the integral part of the enterprise management. On average, about $20 \%$ of the energy expended for management and operational activities in the enterprise is devoted to solving and avoiding conflicts.

The conflict, in its basic sense, has a pejorative connotation. Actually, it acts wholly or partially destructively on the environment and the conflicted parties. The task of the management or the owner of the enterprise are such activities which will prevent totally destructive conflicts, solve the existing ones of this type or use, by means of the conflict transformation, its cumulated energy for the optimum effectiveness of the organization.

Conflict management consists, therefore, in influencing the conflict, and particularly, in recognizing pre-conflict and conflict situations, the choice and application of the appropriate strategy to handle the conflict and to stimulate the constructive forms of competition. At the pre-conflict stage, it is possible to prevent an undesirable situation unless the element of the conflict is consciously introduced by the management. At the moment of the occurrence of the conflict one aims at taking control over it, by solving, softening or stimulating the situations of competition.

In a situation of the spontaneous appearance of the conflict there is required fast reacting to and locating the conflict and the analysis of all of its elements, i.e. 
the subject of the conflict, discrepancies, the parties of the conflict, its duration and dynamics.

Conflict management is based on the research in the field of psychology concerning the nature of the conflict. In these studies there are indicated destructive and constructive conflict processes. (Fig. 1) The destructive results of the conflict may include: stress, sense of threat, negative emotions, aggression, anger, hatred, withdrawal from relationship, deterioration of relationship and communication, departure of people from the organization, and also division, breakdown and liquidation of the organization. The indirect negative effect is the concentration on the conflict and the involvement of the third parties. The positive effects of the conflict include: increase in energy, motivation and trust, sense of justice, specifying the goal, increase in the knowledge of the possibilities of some solutions, revealing dysfunction, triggering competition, gaining experience, technical progress, relieving emotions, learning about people and their views, mobilization, becoming aware of own needs, values and interests, increase in motivation, increase in trust, innovativeness. [Antoszkiewicz, Pawlak 2010, p. 123].

Figure 1. The process of conflict management

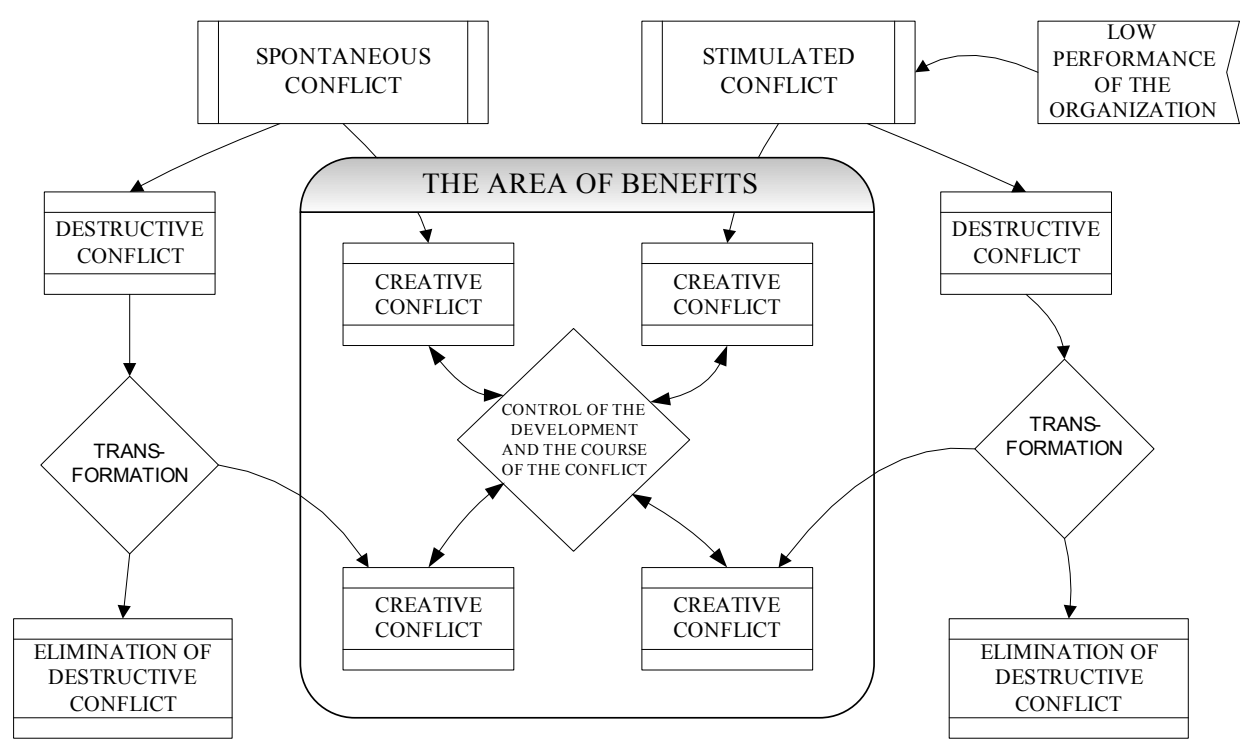

Source: The author's own research.

In the framework of sustainable development, apart from objective and spontaneous conflicts, a certain amount of stimulated, creative conflicts ought to be found in the wallet of the management's activities. At this point, it is necessary to emphasize that some, even unconscious, activities in the framework of conflict 
management may slip out of control and become undesirable, that is, destructive in the end result. They may include the ones, even theoretically, positive but absorbing too much potential of the enterprise in a given moment.

The advantages of the passive strategy may include the low cost and lack of involvement of the manager in the conflict. However, the strategies of this type usually do not solve the conflict but they only soften it, and they sometimes may lead to the escalation of the conflict. Active strategies are the most effective way of solving conflict since they give chances for the permanent solution of the conflict. While selecting the strategy of resolving the conflict, it is necessary to pay attention to: the size of the conflict and the advantages and disadvantages of the strategy. With conflicts involving a greater number of people, one should choose the active strategies. [Antoszkiewicz, Pawlak 2010, p. 63]

The task of the management is directing the conflict and its solving in a way leading to the optimum efficiency of the organization. The optimum effectiveness of the organization requires the conflict at the moderate level.

Managing and controlling the conflict assumes the application of the active strategy towards this phenomenon, even if the conflict becomes destructive and, particularly, when the conflict involves a greater amount of people. The passive strategies are most frequently related to spontaneous conflicts of small intensity. However, it would be a mistake to adopt a passive attitude, especially the abandonment of intervention, in case of unrecognized problems, in which the irrational ones pose a particular threat. Taking immediate actions in case of the last ones, with no involvement in the conflict, with the application of the strategy, appropriate for the situation, is an optimum solution.

The elements of conflict management, given as an example, have a direct impact on the enterprise management, like the change management etc. It is the interference in the enterprise system, whose aim is to either remove threats or counteract apathy and routine and stimulate initiative and creative problem-solving.

The family business is a particular kind of enterprise which, apart from a range of advantages and disadvantages listed above, also has more complicated structure due to the coexistence of three separate sub-systems: the family, the enterprise and the structure of ownership. The sub-systems overlap, contact each other, creating some additional flashpoints for undesirable conflicts. This may become a big load and challenge for the management of the enterprise, who frequently, as family members or relatives, lose the objectivity and the ability of the appropriate assessment of the situation.

Apart from the enterprise management in the standard approach, it is necessary to create the system of conduct, a kind of the family constitution which may regulate the business relationship and the ownership in the family. Of course, each family enterprise is different with respect to the structure and impact of the selected sub- 
systems. It often happens that the family has the autocratic structure of functioning due to the concentration of ownership and experience in the hands of only one person. On the other hand, a reasonable owner must introduce the elements of democracy, most preferably, in a codified way in the form of constitution.

The family constitution should consist in a set of principles which, commonly followed, are to make it possible for the family to cooperate and, in a specific way, to protect business from the perils of the family. Each essential and unsettled family conflict is transferred to the enterprise. The family must create the mechanisms of isolating business from their own problems but, above all, make an attempt to always show unity. The elaboration of this unity is one of the main reasons of creating the family constitution. In this way, the constitution becomes a tool of regulation of everyday work and a tool of solving conflicts. While planning certain solutions, each family must identify the already existing fields of conflicts and their potential places. It ought to establish and describe the procedures of conduct in different possible family situations, such as the insubordination of a family member in the enterprise, including their removal from the enterprise space. [Budziak 2014, p. 10]

Defining the boundaries of the enterprise and the family, establishing the rules, e.g. the procedures and stages of possible succession earlier, sets clear rules and eliminates understatement, speculation and conspiracy, which is, the elements in a straight line generating conflicts [Keyt, McCann http], which, frequently hidden, are difficult to diagnose and which are dangerous for the family business.

At this point, there appears the penetration and abrasion of the two potentials, the enterprise and the family, in the area of the information flow, the example of which may be some informal talks at home, on the current problems in the enterprise. The decisions taken in an informal way do not always get to all the interested parties or they are passed with the delay, and they are frequently deformed. To eliminate the problem of discussing, decision taking, establishing certain activities behind the back of the remaining family members, the above mentioned family constitution ought to establish the rules of communication in the enterprise and in the family in the field of business topics. This will definitely formalize and reduce the family discussions on business but, simultaneously, separate the family issues from the enterprise. This will bring about the improvement in organizational culture in the field of communication and eliminate the majority of the conflicts occurring in relation with the above.

Each family should elaborate the principles of communication in the framework of their own constitution. The frequently used standard is writing down the arrangements in the form of a protocol, e-mail or a note. After the meeting, they are sent to all interested parties. Then, they know all the key arrangements, decisions and operational tasks. Due to these formalities, it is always possible to refer to the 
note, and in case of a conflict situation, it is easier to investigate a mistake was previously made and how to avoid it in the future. [Barcińska 1(2)/2014, p. 12]

To make organizational culture effectively participate in and support the process of conflict management, it is necessary to adjust its (essential) features to its requirements. It is necessary to find out the discrepancies between the desired conditions, from the point of view of the strategy of the family business, and the actual conditions. The phenomenon of discrepancies appearing in different groups on the levels of the organization was called the cultural gap.

Establishing the cultural gap between the reality and the culture, required in the management process and for the strategy development, involves [Urbanowska - Sojkin, Banaszczyk, Witczak 2007, p. 296]:

- conducting the cultural audit to identify the previous organizational culture,

- the analysis and simulation of the future organizational culture, taking into consideration the strategy of conflict management,

- specifying the strategy of transition from the present to the required culture.

The most difficult task is transforming the already existing culture into the culture supporting the processes of conflict management and the overall strategy of the organization. It is a long-term process, since all the changes are connected with the process of learning of both the employees and the owners and the effectiveness of this process depends on their involvement [Urbanowska -Sojkin, Banaszczyk, Witczak 2007, p. 298].

Using the systemic approach towards the issue of conflict management, it is necessary to separate conflicts, which are fully intellectual, from the ones with the emotional background. The purely substantive problems concerning the organization and management must be settled down within the boundaries of the enterprise sub-system by the people directly involved. The problems resulting from the emotional system of the family need to be 'shifted' exclusively onto the family ground.

\section{Conclusions}

In accordance with the theory of systems, all the organisms or more elaborated systems naturally aim at the internal stabilization. To maintain this condition, paradoxically, they must take actions provoking conflicts in their environment. Overcoming barriers and solving problems is inscribed in the functioning of each system. The enterprise, as a system, creates conflicts spontaneously, which are the result of the constant need for development and the achievement of new goals. This is contradictory to the need for stability of the internal sub-systems of the enterprise.

The family business has a more sophisticated structure, which is a catalyst of arising of many conflicts. The conscious conflict management introduces equilibrium 
in the enterprise while leveling unfavorable and using positive phenomena for the performance of overall goals. The element combining the sub-systems of the family enterprise and supporting the effective conflict management is the family constitution. It regulates the relationship - the family-the enterprise, by means of which it directly influences the level of organizational culture and the efficiency of conflict management. Consequently, there comes into being the cause and effect relationship between the three elements: the internal constitution, organizational culture of the family enterprise and the process of conflict management.

\section{References}

Antoszkiewicz D. J., Pawlak Z.: (2010), Techniki menedżerskie - skuteczne zarzadzanie firma, Poltext, Warszawa.

Barcińska K. (2014), Komunikacja w firmie rodzinnej, " Relacje, Magazyn firm rodzinnych", nr 1(2)

Budziak T. (2014), O czym pomyśleć przed tworzeniem konstytucji rodżinnej? Rady prak.tyka," Relacje, Magazyn firm rodzinnych", nr 1(2)

http://www.familybusinessmagazine.com/index.php?/freefeature/single/managing_the_ family_business_overlap, dostęp: 10 lutego 2014

Jeżak J. Winnicka-Popczyk A. Popczyk W. (2004), Præedsiebiorstwo rodzinne funkcjonowanie i rozwóoj, Difin, Warszawa.

Keyt A., McCann G.(2014), Managing the family/business overlap, "Family Business" [online]

Kowalczuk R. Sieczyński T. (eds.) (1987), Psychologia i socjologia pracy, WSiP, Warszawa.

Safin K. (2007), Przedsiębiorstwa rodzinne - istota $i$ zachowania strategiczne, WAE im Oskara Langego, Wrocław.

Tomski P. (2013), O przewagach konkurencyjnych firm rodzinnych w kontekśsie teorii zasobowej, „Przedsiębiorczość i Zarządzanie”, tom XIV, zeszyt 6, część II, Wydawnictwo SAN, pp. 121-130

Trutkowski C. (ed) (2006), Podrecznike dobrych praktyk, WN Scholar, Warszawa.

Urbańska-Sojkin E. Banaszczyk P. Witczak H. (2007), Zarz̨qdzanie strategiczneprz̨edsiębiorstwem, PWE, Warszawa. 